\title{
Estructura familiar y nivel de logro en niños y niñas de escuelas públicas de Arequipa
}

\author{
Family Structure and School Achievement in Boys and Girls from \\ Arequipa Public Schools
}

\author{
Walter Lizandro Arias Gallegos \\ Ana Cecilia Quispe Álvarez \\ Karla Denisse Ceballos Canaza \\ Universidad Católica San Pablo, Perú \\ Correspondencia: warias@ucsp.edu.pe
}

Recibido: 18-12-2015

Aceptado: 15-03-2016

\section{Resumen}

En este estudio se analizan las relaciones entre la estructura familiar y el nivel de logro escolar en 780 estudiantes de colegios públicos, de la ciudad de Arequipa, de nivel primario. Las notas se valoraron cualitativamente según las disposiciones del Ministerio de Educación: AD, A, B y C. Se utilizó una ficha de recojo de datos diseñada ad hoc para los fines del estudio y, para el procesamiento de datos, se utilizó la prueba chi cuadrado. Los resultados revelan que las mujeres presentan mejor rendimiento que los varones, excepto en el área lógico matemática, y que las mujeres provienen de hogares mejor constituidos, siendo sus padres casados en el $66.3 \%$ de los casos. Con respecto al nivel de logro, el porcentaje de los estudiantes de las familias nucleares, reconstruidas y extendidas fue mayor que en las familias comunitarias y monoparentales. Las asociaciones halladas fueron significativas en la mayoría de los casos ( $<<0.05)$. Palabras clave: Estructura familiar, logro escolar, tipo de familia.

\begin{abstract}
In this study we analyzed the relations between family structure and the level of school achievement in 780 students from public elementary schools in Arequipa. The grades were evaluated qualitatively according to the dispositions of the Ministry of Education: $\mathrm{AD}, \mathrm{A}, \mathrm{B}$ and $\mathrm{C}$. For the ends of the study we used an ad-hoc data sheet and for data
\end{abstract}


processing the chi-square test. The results show that women have better performance than men except in mathematical logic area, and women come from better constituted homes, being his parents married in $66.3 \%$ of the cases. With regard to the level of achievement, we found that the percentage of students who came from nuclear family structure, so as rebuilt and extended family structures, was higher than community and single parent families. Significant associations were found in most cases ( $<<0.05)$.

Key words: Family structure, school achievement, type of family.

\section{Introducción}

El rendimiento escolar es una de las variables más estudiadas en el campo de la psicología educativa. Puede definirse como el grado de conocimiento demostrado en un área, que se mide de manera más frecuente por el promedio de las calificaciones (Gaxiola, González, Contreras \& Gaxiola, 2012). Pero, aunque esta definición es operativa, resulta limitante, pues no toma en cuenta los aspectos afectivos y motivacionales del alumno, así como habilidades y destrezas más allá del conocimiento como tal.

En ese sentido, una definición más centrada en las destrezas sería la que nos da Pizarro y Clark (1998) cuando dicen que el rendimiento académico «es una medida de la capacidad de respuesta del individuo que expresa en forma estimativa, lo que una persona ha aprendido como resultado de un proceso de instrucción o formación» (citado por Espinoza, 2009, p. 223). De manera similar, García-Zapatero (1983) define el rendimiento escolar como «la expresión de las capacidades del estudiante desarrolladas a través del proceso de enseñanza-aprendizaje que le posibilita obtener un nivel de funcionamiento y logros académicos a lo largo de su periodo escolar» (p. 62).

Sin embargo, un problema que subyace a las definiciones es el del proceso de evaluación, ya que la evaluación cuantitativa tiende a encasillar al alumno y sirve más para clasificar y tipificar que para valorar realmente el aprendizaje (Bocanegra, 2009). Así, el proceso de evaluación juega en contra del alumno, pues aquel que logra deficientemente el programa establecido o no lo hace más allá del límite explícitamente determinado es considerado como estudiante de bajo rendimiento escolar, independientemente de sus motivos, intereses, vivencias personales, etc. (Cuevas, 2005). Por eso, podemos decir con Escudero (2005) que el fracaso es una realidad construida en y por la escuela, en sus múltiples relaciones con los estudiantes y con la sociedad. Y como dice este autor, el fracaso escolar es como un paraguas que acoge múltiples realidades, de modo que cabe preguntarse si el fracaso escolar es realmente del alumno o del profesor, de la escuela o de los padres. En esa medida, es importante comprender las relaciones entre las diversas variables que determinan el rendimiento escolar. 
Por ejemplo, en el estudio de Espinoza (2009), con más de 500 alumnos de primero de secundaria, se encontró que las variables que se relacionaban con el rendimiento escolar fueron la autoestima, la autoconfianza, el clima escolar y el nivel socioeconómico del hogar al que pertenecen los estudiantes. De ahí que algunos autores prefieren diferenciar entre los factores externos y los internos del fracaso escolar (Moreno, 2009). Entre los primeros se ubican los factores familiares, la escuela, la sociedad, etc.; y dentro de la categoría de los internos están las condiciones psicológicas, intelectuales y emocionales de los estudiantes, que, en realidad, están mediadas por los primeros.

Una de las variables que más se ha estudiado en relación con el rendimiento escolar es la inteligencia (Good \& Brophy, 1999), y se ha observado que mientras mayor es la capacidad intelectual, mayor es también el rendimiento académico, aunque eso no implica que diversos factores emocionales puedan interferir entre ambas variables e impactar en el rendimiento escolar (Soriano, 2008). Una de las variables emocionales que afecta negativamente el rendimiento escolar es la ansiedad, ya que altos niveles de ansiedad reducen la eficacia del aprendizaje, porque disminuye la atención (Jadué, 200o). En el estudio de García-Zapatero (1983) se halló una relación inversa entre la ansiedad y el rendimiento académico de 703 estudiantes de entre 12 y 16 años, además, la ansiedad estaba más presente entre los varones que entre las mujeres. Un estudio más actual reportó que, en una muestra de 469 alumnos de 4.to y 5.to de secundaria, la ansiedad ante los exámenes se relacionó con las estrategias de adquisición y codificación de la información, pero estas relaciones eran bajas y negativas (Alegre, 2013).

Precisamente, el peso de los factores individuales ha recaído de la mano de la psicología cognitiva, en el procesamiento de la información (Miljánovich, Quesada, Atalaya, Huerta, Aliaga \& Evangelista, 2005). En esa línea hay estudios que han relacionado, por ejemplo, la capacidad de lectura con el rendimiento académico. En el trabajo de Condemarín y Scagliotti (1979), que se basó en una muestra de niños chilenos entre los 7 y los 13 años, se encontró que la habilidad para leer predecía el rendimiento académico, además, la repitencia se asoció con una baja capacidad de asimilación verbal y para establecer semejanzas, sobre todo en las niñas.

Otra variable interna que se ha estudiado con respecto al rendimiento escolar es la motivación de logro, ya que las personas que tienen alta motivación de logro suelen ser optimistas, perseverantes e innovadoras, se hacen responsables de sus resultados, se plantean metas realistas y buscan el éxito futuro. Estas cualidades se han asociado con un mayor rendimiento académico, sin embargo, en una investigación hecha en el Perú, los alumnos de colegios públicos presentaron mayor motivación de logro académico que los que provenían de colegios privados, pero estos últimos tenían mayor rendimiento académico. Además, el sexo influyó en el rendimiento a favor de las mujeres, pero no la motivación de logro (Thornberry, 2003). En esta misma línea, las metas educativas se relacionan directamente con el rendimiento académico. En 
el estudio de Gaxiola et al. (2012) se encontró, por ejemplo, que los niños resilientes se encuentran menos afectados por las condiciones de vida, y que, más bien, su capacidad de autorregulación predijo sus metas educativas que se relacionaron con su rendimiento académico. Los niños no resilientes, por el contrario, fueron más susceptibles a las condiciones de vida desfavorables y su capacidad de resiliencia no tuvo efecto en el rendimiento académico.

En ese sentido, pasando ya a los factores externos, tenemos que las condiciones de vida son cruciales para potenciar el aprendizaje de los estudiantes. Los estudios pioneros de Majluf (1993) con niños que vivían en situaciones de pobreza dan cuenta de cómo la marginalidad afecta el desarrollo de la capacidad intelectual y tiene efectos negativos en el rendimiento académico. De hecho, esta autora introdujo el término «síndrome de carencias múltiples» para referirse a los efectos psicológicos de las condiciones de vida pluricarenciales, tanto biológica como psicológica y socialmente. A nivel biológico, los estudios de Pollitt (2002) señalan cómo los factores nutricionales, expresados en la carencia de hierro, yodo y diversos micronutrientes y mediados por el nivel socioeconómico, se asocian con el retraso escolar. En Arequipa, pudimos demostrar que los niños de nivel primario de una educación educativa pública, ubicada en una zona urbano-marginal, presentan limitaciones en su memoria de trabajo, y que este déficit está relacionado con la calidad de los alimentos que consumen, siendo los niños que reciben una alimentación más balanceada los que presentan mejor capacidad de memoria (Arias, Sancho, Lévano \& Collado, 2014).

En ese aspecto, a nivel sociocultural, es un hecho común que las familias de nivel socioeconómico bajo no tienen interés en favorecer la educación de sus hijos, les apoyan poco en sus estudios y presentan problemas psicosociales como alcoholismo, delincuencia y desintegración familiar (Jadué, 2003). Siguiendo esta línea, un estudio reciente demostró que, en la ciudad de Arequipa, los niveles de integración familiar son bajos, y que variables como el nivel socioeconómico, los ingresos familiares y el nivel educativo de los padres tienen un efecto moderado en la integración familiar (Castro, Arias, Dominguez, Masías, Salas, Canales \& Flores, 2013). Por ello, el presente estudio se centra en la estructura familiar como base para un rendimiento escolar satisfactorio, ya que la familia tiene efectos en la conducta de la persona, particularmente de los niños y jóvenes que se encuentran en proceso de formación. En comunicaciones previas hemos indicado que la violencia familiar tiene efectos directos en la agresividad de los hijos (Arias, 2013), teniendo como repercusiones más resaltantes la delincuencia, los problemas del desarrollo, deficiencias perceptuales y motoras, bajo aprovechamiento escolar, depresión, ansiedad y baja autoestima (Frías, Rodríguez \& Gaxiola, 2003).

Para comprender el fenómeno de la desintegración familiar, tenemos que partir del hecho de que las familias han cambiado en los últimos años: su configuración, su estructura y la dinámica familiar ya no son las mismas. Entre los factores que han tenido injerencia en 
el cambio de las estructuras familiares, sobresalen la creciente individualidad, la mayor movilidad geográfica y la entrada masiva de la mujer al mundo laboral (Jadué, 2003). A ello se suman las altas tasas de divorcio que, aunadas al trabajo de ambos padres y la alta tecnologización, terminan por separar física y/o emocionalmente a las familias y sus miembros.

La familia como organismo social básico tiene un ciclo de vida y una estructura que está constituida por holones individuales, conyugales, parentales y fraternales (Arias, 2012). Ello condiciona la existencia de familias nucleares, extendidas, comunales, reconstruidas y monoparentales; aunque, según algunos autores, las diversas tipologías familiares, más allá de su utilidad taxonómica, no hacen sino distorsionar la esencia de la familia (Guerra, 2004), cuyo bienestar radica en la comunión de intereses y afectos (Caffarra, 2011), otros enfatizan la calidad de los vínculos y relaciones familiares (Hellinger, 2005; Minuchin, 2003).

No se puede negar, empero, que el funcionamiento familiar es un excelente predictor del desarrollo de los hijos. Entre los factores familiares que condicionan las conductas disfuncionales figuran la desintegración familiar, la hostilidad, la disciplina drástica y la conducta criminal o alcoholismo del padre. En el estudio de Frías, Corral, López, Díaz y Peña (2001), la ingesta de alcohol del padre, la conducta delictiva y las habilidades sociales del adolescente explicaban el $29 \%$ de la varianza en sus problemas escolares. De hecho, las habilidades sociales de los escolares también se han asociado con el bajo rendimiento escolar (Navarro, s/f). En consecuencia, niños criados bajo condiciones de abuso físico o emocional, expuestos a conflictos familiares y maritales, tienen más posibilidades de desarrollar trastornos emocionales (Jadué, 200o), que se manifiestan en baja autoestima, falta de confianza (Garrido Lecca, 1997; Garrido Lecca \& Figueroa, 1992) y hasta síndromes psiquiátricos que afectan su rendimiento escolar y su trayectoria académica en diversos niveles educativos (Rodríguez, 2003).

Por otro lado, las condiciones de violencia o de riesgo psicosocial de la familia no son las únicas causas del bajo rendimiento escolar atribuibles a la familia, ya que la falta de apoyo o la ausencia de los padres son igualmente factores muy importantes en el desenvolvimiento académico de los hijos. Un estudio de Beltrán (2013) reveló que el nivel de estudio de los padres y el tiempo que dedican a sus hijos afectan de manera positiva sus logros académicos, de modo que cada hora de estudio reduce la probabilidad de retraso académico. Por ejemplo, cada nivel educativo adicional de los padres reduce en $4 \%$ el atraso escolar; una hora de atención de la madre reduce la probabilidad de atraso en 1.6\% (Beltrán, 2013).

Evidentemente, el trabajo de los padres es un factor que juega en contra de la escolaridad de los hijos, cuando no se hace un uso responsable del tiempo de los padres en casa, ya que, por ejemplo, los infantes de madres que no trabajan tienen un apego seguro, mientras que los de las madres que trabajan tienen un apego inseguro (Portilla, Carrillo \& Gonzales, 2008). En ese sentido, el hecho de que los padres se divorcien u otras causas obligan a las madres a trabajar, restándoles el tiempo que pasan con sus hijos. Entre los motivos que hacen que un padre o madre no esté presente en el hogar se tiene la migración, la cárcel, 
el fallecimiento, el divorcio, el abandono y la enfermedad (Arias L., 2013). Sin embargo, la monoparentalidad no siempre es un factor de riesgo, ya que en una investigación de Oporto y Zanabria (2006) no se halló relación entre la estructura familiar y el desarrollo emocional de niños entre ocho y diez años, aunque se encontró que los varones son más vulnerables y que los niños de familias nucleares son más empáticos que los de familias monoparentales, quienes resultaron tener mayores niveles de autoconciencia.

El presente estudio pretende valorar las relaciones entre la estructura familiar y el rendimiento escolar de niños y niñas de instituciones educativas públicas de la ciudad de Arequipa, bajo el supuesto de que los niños que provienen de familias nucleares presentan mejor rendimiento escolar que sus pares que provienen de familias con otras estructuras.

\section{Método}

\section{Participantes}

La muestra está conformada por 813 escolares de primero a sexto de primaria de dos instituciones públicas de la ciudad de Arequipa. El $66.3 \%$ son varones y el $33.7 \%$ son mujeres. El $9 \%$ está en primer grado de primaria, el $16.4 \%$, en segundo, el $15.7 \%$, en tercero, el 17.7 \%, en cuarto, $21.5 \%$, en quinto, y el 19.1\%, en sexto. No obstante, debido a que no en todos los casos se contó con fichas con los datos completos, es que, al final, la muestra válida fue de 780 estudiantes.

\section{Instrumentos}

Para la recolección de los datos se elaboró una ficha ad hoc, que contenía información de la institución educativa (nombre y tipo de gestión), el/la estudiante (nombre, sexo y grado de estudio), la familia de origen (estado civil de los padres, número de hijos de los padres, tipo de familia y número de personas que habitan en la casa) y su rendimiento escolar expresado en el nivel de logro (AD, A, B y C) en dos áreas esenciales, como son comunicación integral y lógico matemática, y el nivel de logro global del estudiante.

\section{Procedimiento}

El procedimiento de recolección de la información implicó el entrenamiento de los profesores tutores de aula, quienes aplicaron el instrumento en horario de clases. Previamente se solicitó la autorización de la persona a cargo de la dirección, quien delegó la organización y coordinación de la capacitación de los profesores y la recolección de la información. El recojo de los datos se hizo solicitando el consentimiento informado de los padres de familia, explicando los objetivos del estudio y apelando a su sinceridad. Los profesores colocaban las notas de los estudiantes en la ficha de 
datos y luego se procesó la información mediante técnicas de estadística inferencial. Estas notas se consignaron de manera cualitativa: AD (logro sobresaliente), A (logro obtenido), B (logro en proceso) y C (desempeño deficiente), por lo que se les asignó valores ordinales, al igual que al ciclo de estudios. El sexo y el tipo de la familia, así como el estado civil de los padres, se consideraron en un nivel de medición nominal. En consecuencia, el procesamiento de la información se hizo mediante la prueba chi cuadrado y se obtuvieron valores descriptivos de las variables de estudio.

\section{Resultados}

En primer lugar, tenemos que el número de hijos promedio fue de 1.772 dentro de un rango de 1 a 11 hijos y con una desviación estándar de \pm 0.300 . El número de personas que viven en casa fue en promedio de 5.847 personas, con una desviación estándar de \pm 3.438 y un rango de 2 a 16 personas. La mayoría de hogares fueron nucleares (49.56\%), seguidos del tipo de familia extendida (29.76\%), las familias monoparentales (8.36\%), las familias reconstruidas $(8.9 \%)$ y las familias comunitarias $(3.42 \%)$. En cuanto al nivel de logro, tenemos que el $6.1 \%$ obtuvo el calificativo de sobresaliente en el área de comunicación integral, el $73.7 \%$ obtuvo el calificativo de A, el 18.9\%, B, y 1.4 \%, el calificativo de C. En el área de lógico matemática, los porcentajes fueron $4.6 \%$ sobresaliente, $70.6 \%$ óptimo, $23.3 \%$ en proceso y $1.5 \%$ deficiente. En cuanto al logro global, el $5.3 \%$ obtuvo AD, el $72.7 \%$, A, $21 \%$, B, y el 1 \%, C.

\section{Tabla 1.}

Tabla de contingencia sexo * nivel de logro en comunicación integral

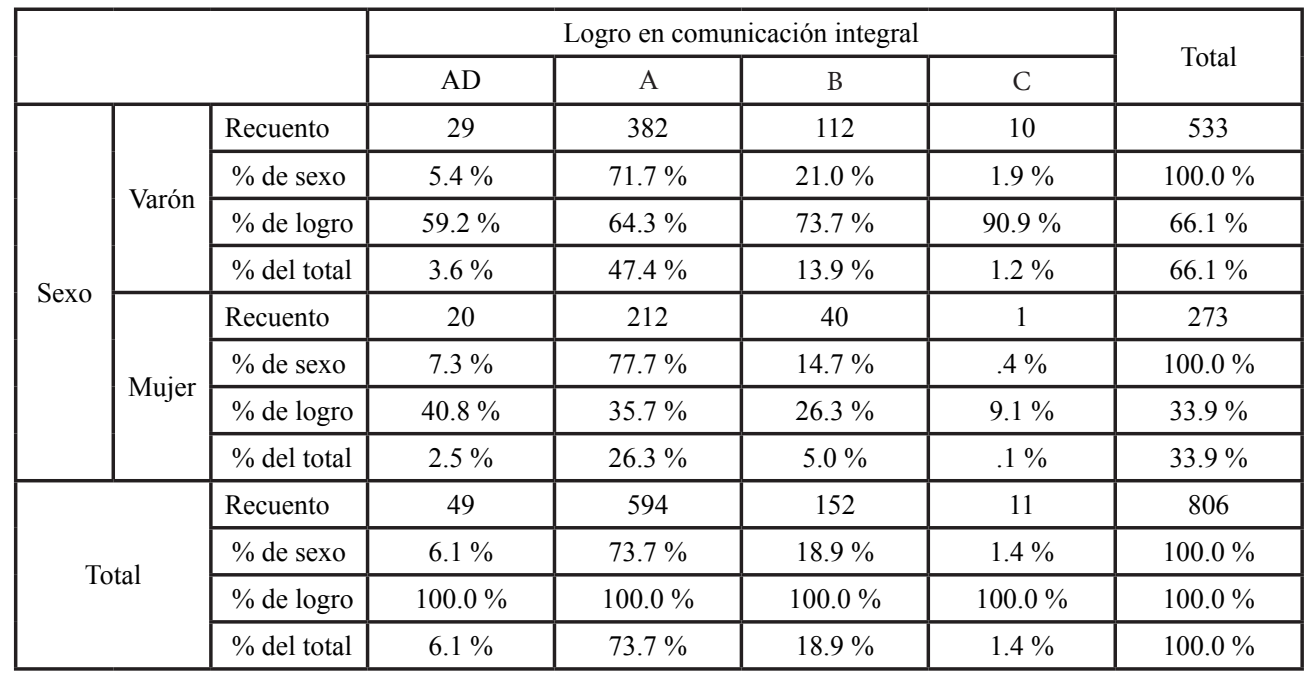

$\mathrm{X}^{2}=8.822 ; \mathrm{gl}=3 ; \mathrm{p}<0.031$ 
Para analizar las relaciones entre las variables, dado que son de carácter cualitativo, se trabajó con tablas de contingencia y, para valorar el grado de asociación entre ellas, se aplicó la prueba chi cuadrado. En la Tabla 1 podemos apreciar que, en función del sexo de los estudiantes, las mujeres tienen un mayor porcentaje de calificativo $\mathrm{AD}(7.3 \%)$, en comparación con los varones (5.4\%), y lo mismo ocurre con el calificativo A ( $71.7 \%$, los varones, y $77.7 \%$, las mujeres). Obviamente, lo inverso ocurre con el calificativo de B, donde los varones son la mayoría (21 \%) y las mujeres minoría (14.7\%), y el calificativo de C (varones, $1.9 \%$ y mujeres, $0.4 \%$ ). Todos estos valores son significativos $(\mathrm{p}<0.031)$ a través del análisis con la prueba chi cuadrado.

\section{Tabla 2.}

Tabla de contingencia sexo * nivel de logro en lógico matemática

\begin{tabular}{|c|c|c|c|c|c|c|c|}
\hline & \multicolumn{4}{|c|}{ Logro en lógico matemática } & \multirow{2}{*}{ Total } \\
\hline & & & $\mathrm{AD}$ & A & B & $\mathrm{C}$ & \\
\hline \multirow{8}{*}{ Sexo } & \multirow{4}{*}{ Varón } & Recuento & 29 & 369 & 126 & 9 & 533 \\
\hline & & $\%$ de sexo & $5.4 \%$ & $69.2 \%$ & $23.6 \%$ & $1.7 \%$ & $100.0 \%$ \\
\hline & & $\%$ de logro & $78.4 \%$ & $64.9 \%$ & $67.0 \%$ & $75.0 \%$ & $66.1 \%$ \\
\hline & & $\%$ del total & $3.6 \%$ & $45.8 \%$ & $15.6 \%$ & $1.1 \%$ & $66.1 \%$ \\
\hline & \multirow{4}{*}{ Mujer } & Recuento & 8 & 200 & 62 & 3 & 273 \\
\hline & & $\%$ de sexo & $2.9 \%$ & $73.3 \%$ & $22.7 \%$ & $1.1 \%$ & $100.0 \%$ \\
\hline & & $\%$ de logro & $21.6 \%$ & $35.1 \%$ & $33.0 \%$ & $25.0 \%$ & $33.9 \%$ \\
\hline & & $\%$ del total & $1.0 \%$ & $24.8 \%$ & $7.7 \%$ & $.4 \%$ & $33.9 \%$ \\
\hline \multirow{4}{*}{\multicolumn{2}{|c|}{ Total }} & Recuento & 37 & 569 & 188 & 12 & 806 \\
\hline & & $\%$ de sexo & $4.6 \%$ & $70.6 \%$ & $23.3 \%$ & $1.5 \%$ & $100.0 \%$ \\
\hline & & $\%$ de logro & $100.0 \%$ & $100.0 \%$ & $100.0 \%$ & $100.0 \%$ & $100.0 \%$ \\
\hline & & $\%$ del total & $4.6 \%$ & $70.6 \%$ & $23.3 \%$ & $1.5 \%$ & $100.0 \%$ \\
\hline
\end{tabular}

$\mathrm{x}^{2}=3.382 ; \mathrm{gl}=3 ; \mathrm{p}<0.336$

En la Tabla 2 tenemos los resultados del cruce de datos entre el sexo y el nivel de logro obtenido en el área de lógico matemática. Se puede ver que los varones se ubican en mayor porcentaje (5.4\%) que las mujeres en el calificativo de AD (2.9\%). Aunque en el calificativo de A, son las mujeres quienes tienen este nivel de logro en mayor medida (73.3\%) que los varones $(69.2 \%)$. En el nivel B (logro en proceso), los varones se ubican aquí en mayor medida (23.6\%) que las mujeres (22.7\%), al igual que en el nivel C (varones, $1.7 \%$ y mujeres, $1.1 \%)$; las diferencias, sin embargo, no fueron significativas $(\mathrm{p}<0.336)$. 
Tabla 3.

Tabla de contingencia sexo * nivel de logro global

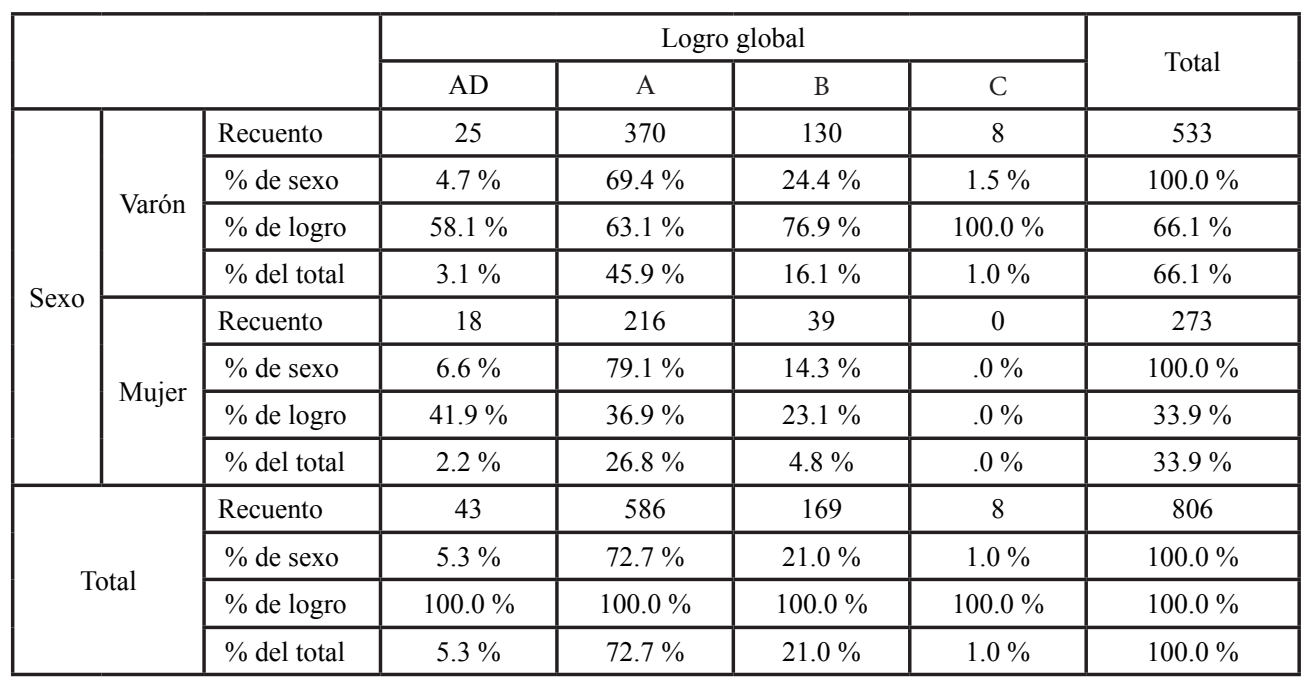

$\mathrm{X}^{2}=16.451 ; \mathrm{gl}=3 ; \mathrm{p}<0.000$

En la Tabla 3 se tienen los datos del sexo y el nivel de logro global. Las mujeres se ubican en un $6.6 \%$ en el nivel AD de logro, mientras que los varones, en un $4.7 \%$. El 79.1 \% de estudiantes mujeres y el $69.4 \%$ de varones se ubica en el nivel A, 24.4 \% de varones y $14.3 \%$ de mujeres se ubica en el nivel de logro B, mientras que el $1.5 \%$ de varones se ubica en $\mathrm{C}$. Estos datos son altamente significativos $(\mathrm{p}<\mathrm{o.0oo})$, por lo que podemos señalar que las mujeres presentan mayor nivel de logro que los varones, aunque estos parecen tener niveles más sobresalientes en matemática, porcentualmente, las mujeres presentan mejor rendimiento. 


\section{Tabla 4.}

Tabla de contingencia sexo * estado civil de los padres

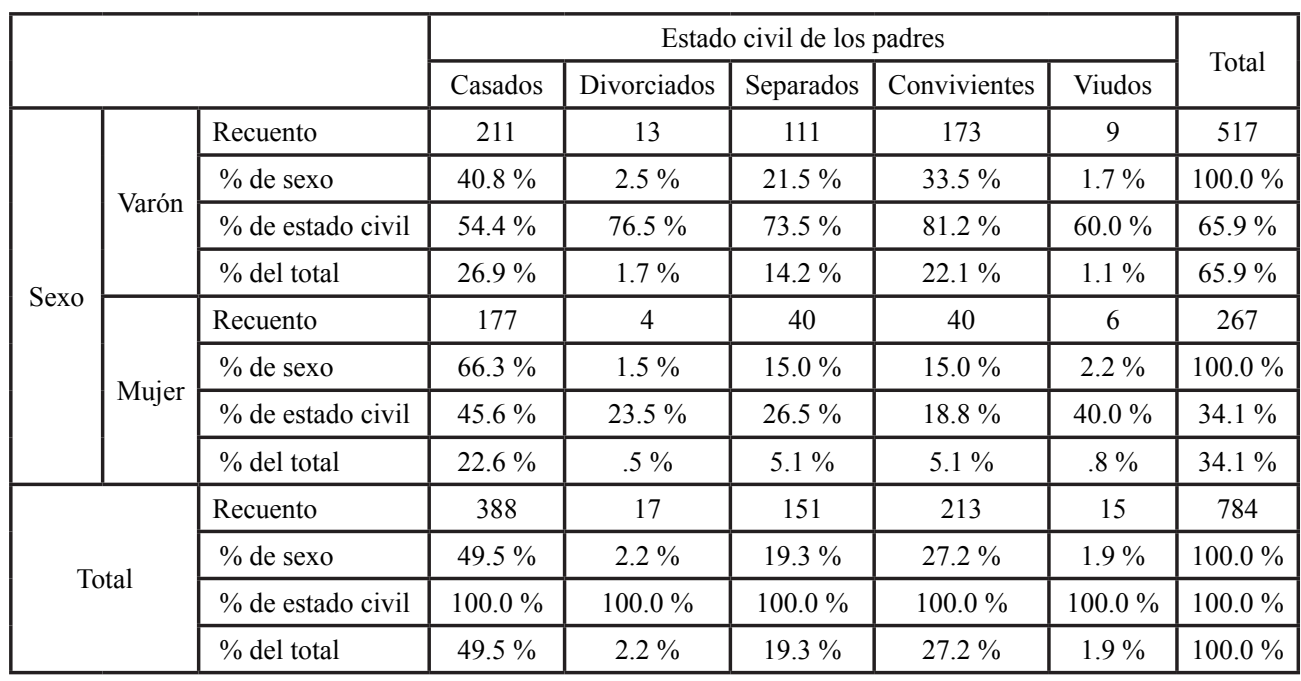

$\mathrm{x}^{2}=50.156 ; \mathrm{gl}=4 ; \mathrm{p}<0.000$

También se analizó la constitución familiar en función del sexo de los estudiantes. En la Tabla 4, se cruzaron los valores de tipo de familia y el sexo, obteniendo como resultado que, mientras en el $40.8 \%$ de los varones sus padres se encuentran casados, la cifra para las mujeres es de $66.3 \%$. Asimismo, los porcentajes de padres divorciados, separados, convivientes y viudos son mayores en los estudiantes de sexo masculino que en los de sexo femenino. Los valores fueron altamente significativos $(\mathrm{p}<0.000)$. 
Tabla 5.

Tabla de contingencia sexo * tipo de familia

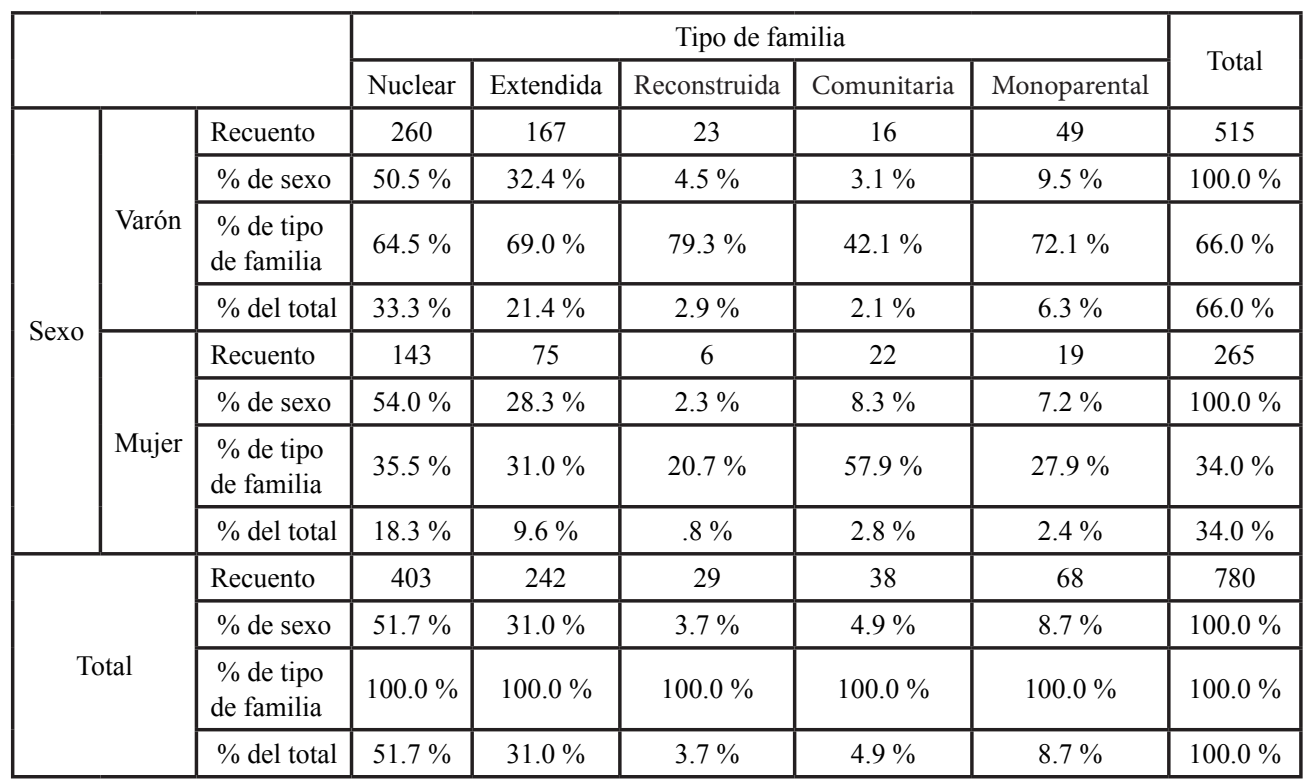

$\mathrm{X}^{2}=14.447 ; \mathrm{gl}=4 ; \mathrm{p}<0.006$

En la Tabla 5 se tienen las variables de sexo y tipo de familia, donde se aprecian datos similares al caso anterior, es decir que la mayoría de estudiantes mujeres provienen de familias nucleares y entre ellas hay menor proporción de familias extendidas, reconstruidas, comunitarias y monoparentales, con respecto a los varones. Los datos también se encuentran dentro de los límites de significancia estadística $(\mathrm{p}<0.006)$. 


\section{Tabla 6.}

Tabla de contingencia estado civil de los padres * nivel de logro en comunicación integral

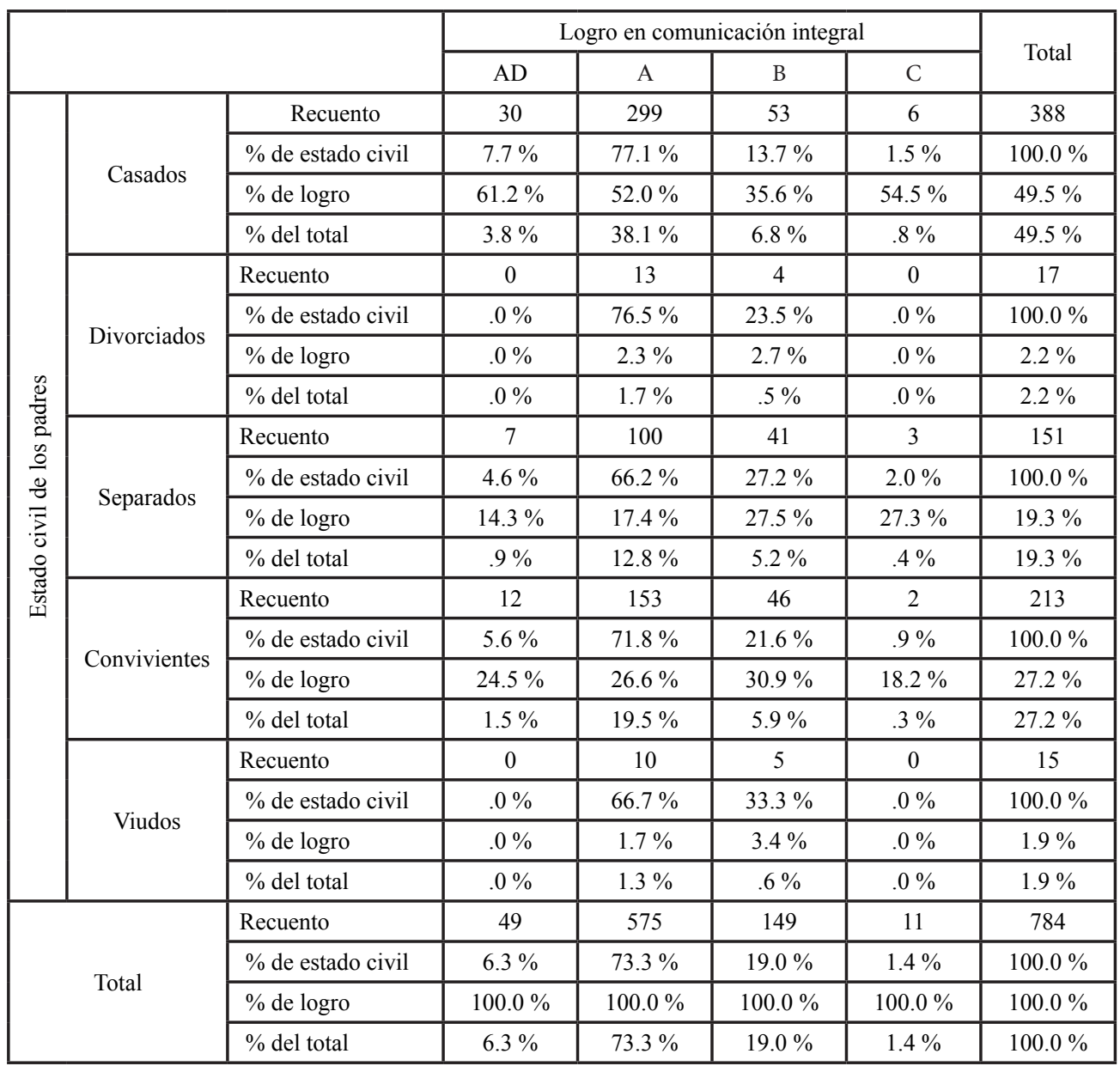

$\mathrm{X}^{2}=20.939 ; \mathrm{gl}=12 ; \mathrm{p}<0.051$

En la Tabla 6 se tiene el cruce del estado civil de los padres y el nivel de logro en comunicación integral. Como se aprecia, el 7.7 \% de estudiantes cuyos padres están casados se ubican en el nivel AD (sobresaliente), siguiéndole los hijos de padres convivientes (5.6\%) y separados (4.6\%), mientras que ningún estudiante cuyos padres estén divorciados o que sean viudos se ubica en este nivel. En el nivel de logro A, se ubican primero los hijos de padres casados (77.1\%), y les siguen los hijos de padres divorciados $(76.5 \%)$, los de padres convivientes (71.8\%), de padres viudos $(66.7 \%)$ y de padres separados (66.2 \%). En el nivel de logro B hay mayor cantidad de hijos de padres viudos (33.3\%), de padres separados (27.2 \%), de padres divorciados (23.5\%) y de padres casados; mientras 
que, en el nivel de logro $C$, el orden es el siguiente: separados (2\%), casados (1.5\%) y convivientes (0.9\%). Estos resultados son significativos al $\mathrm{p}<0.051$.

Tabla 7 .

Tabla de contingencia estado civil de los padres * nivel de logro en lógico matemática

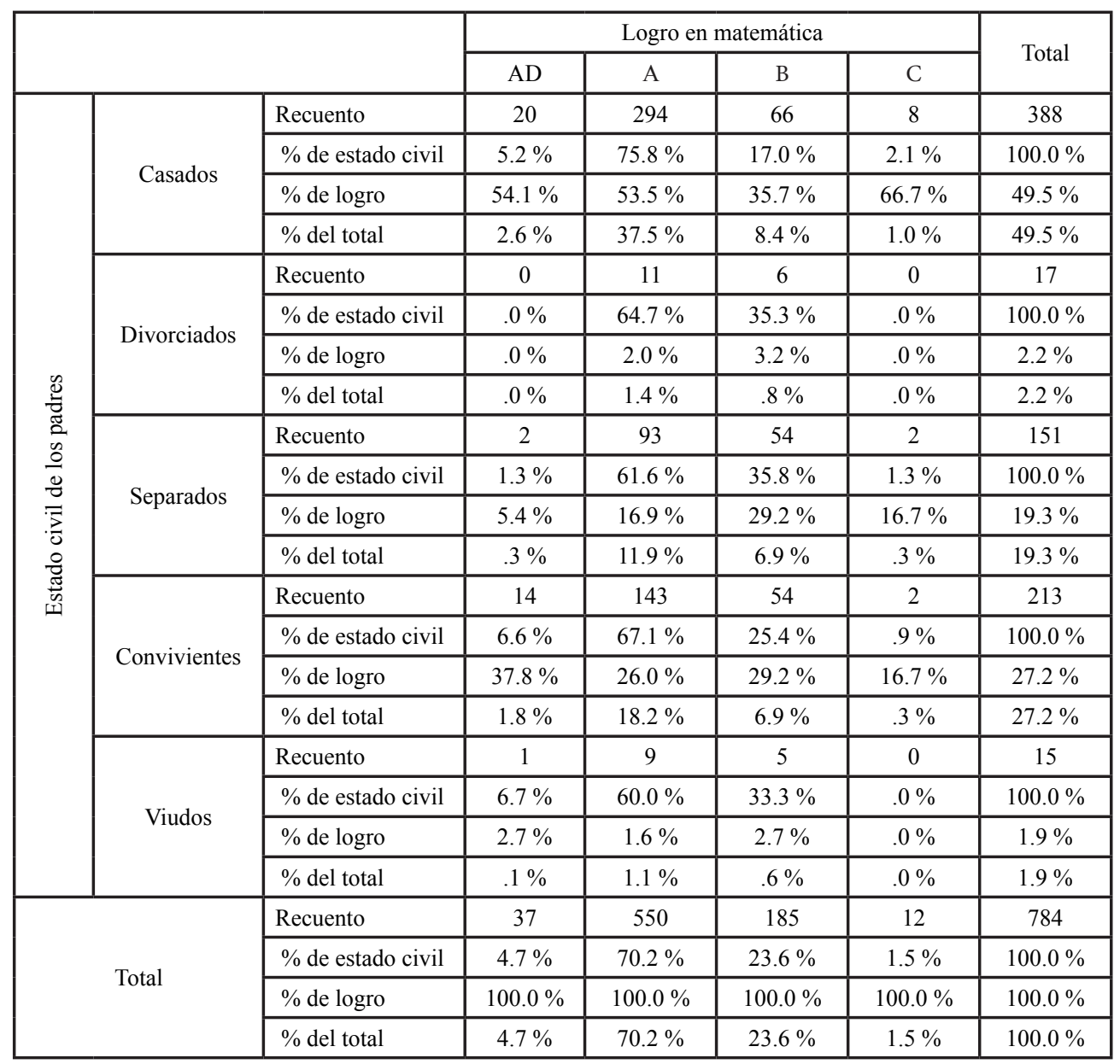

$\mathrm{X}^{2}=30.414 ; \mathrm{gl}=12 ; \mathrm{p}<0.002$

En el caso del cruce del estado civil de los padres con el nivel de logro en el área de lógico matemática, la Tabla 7 expone los resultados. El 6.7 \% de hijos de padres viudos se ubica en $\mathrm{AD}$, y les siguen los hijos de padres convivientes (6.6\%), los hijos de padres casados $(5.2 \%)$ y de padres separados (1.3\%). Ningún estudiante cuyos padres están divorciados alcanza el nivel de logro sobresaliente. En el nivel A, el orden se da así: $75.8 \%$ de hijos de padres casados, $67.1 \%$ de hijos de padres que conviven, $64.7 \%$ de padres divorciados, $61.6 \%$ de hijos de padres separados y $60 \%$ de hijos de padres 
viudos. En el nivel B, el orden es como sigue: $35.8 \%$ de hijos de padres separados, $35.3 \%$ de hijos de padres divorciados, $33.3 \%$ de hijos de padres viudos, $25.4 \%$ de hijos de padres convivientes y $17 \%$ de hijos de padres casados. En cuanto al nivel C, se tiene el $2.1 \%$ de hijos de padres casados, el 1.3\% de hijos de padres separados y el $0.9 \%$ de hijos de padres que conviven. Los resultados fueron altamente significativos $(\mathrm{p}<0.002)$.

\section{Tabla 8.}

Tabla de contingencia estado civil de los padres * nivel de logro global

\begin{tabular}{|c|c|c|c|c|c|c|c|}
\hline & \multicolumn{4}{|c|}{ Logro global } & \multirow{2}{*}{ Total } \\
\hline & & & $\mathrm{AD}$ & $\mathrm{A}$ & B & $\mathrm{C}$ & \\
\hline \multirow{20}{*}{ 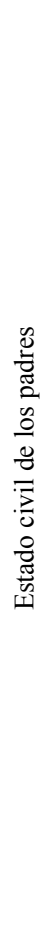 } & \multirow{4}{*}{ Casados } & Recuento & 27 & 300 & 57 & 4 & 388 \\
\hline & & $\%$ de estado civil & $7.0 \%$ & $77.3 \%$ & $14.7 \%$ & $1.0 \%$ & $100.0 \%$ \\
\hline & & $\%$ de logro & $62.8 \%$ & $52.8 \%$ & $34.5 \%$ & $50.0 \%$ & $49.5 \%$ \\
\hline & & $\%$ del total & $3.4 \%$ & $38.3 \%$ & $7.3 \%$ & $.5 \%$ & $49.5 \%$ \\
\hline & \multirow{4}{*}{ Divorciados } & Recuento & 0 & 13 & 4 & 0 & 17 \\
\hline & & $\%$ de estado civil & $.0 \%$ & $76.5 \%$ & $23.5 \%$ & $.0 \%$ & $100.0 \%$ \\
\hline & & $\%$ de logro & $.0 \%$ & $2.3 \%$ & $2.4 \%$ & $.0 \%$ & $2.2 \%$ \\
\hline & & $\%$ del total & $.0 \%$ & $1.7 \%$ & $.5 \%$ & $.0 \%$ & $2.2 \%$ \\
\hline & \multirow{4}{*}{ Separados } & Recuento & 3 & 96 & 50 & 2 & 151 \\
\hline & & $\%$ de estado civil & $2.0 \%$ & $63.6 \%$ & $33.1 \%$ & $1.3 \%$ & $100.0 \%$ \\
\hline & & $\%$ de logro & $7.0 \%$ & $16.9 \%$ & $30.3 \%$ & $25.0 \%$ & $19.3 \%$ \\
\hline & & $\%$ del total & $.4 \%$ & $12.2 \%$ & $6.4 \%$ & $.3 \%$ & $19.3 \%$ \\
\hline & \multirow{4}{*}{ Convivientes } & Recuento & 12 & 149 & 50 & 2 & 213 \\
\hline & & $\%$ de estado civil & $5.6 \%$ & $70.0 \%$ & $23.5 \%$ & $.9 \%$ & $100.0 \%$ \\
\hline & & $\%$ de logro & $27.9 \%$ & $26.2 \%$ & $30.3 \%$ & $25.0 \%$ & $27.2 \%$ \\
\hline & & $\%$ del total & $1.5 \%$ & $19.0 \%$ & $6.4 \%$ & $.3 \%$ & $27.2 \%$ \\
\hline & \multirow{4}{*}{ Viudos } & Recuento & 1 & 10 & 4 & 0 & 15 \\
\hline & & $\%$ de estado civil & $6.7 \%$ & $66.7 \%$ & $26.7 \%$ & $.0 \%$ & $100.0 \%$ \\
\hline & & $\%$ de logro & $2.3 \%$ & $1.8 \%$ & $2.4 \%$ & $.0 \%$ & $1.9 \%$ \\
\hline & & $\%$ del total & $.1 \%$ & $1.3 \%$ & $.5 \%$ & $.0 \%$ & $1.9 \%$ \\
\hline & \multirow{4}{*}{ Total } & Recuento & 43 & 568 & 165 & 8 & 784 \\
\hline & & $\%$ de estado civil & $5.5 \%$ & $72.4 \%$ & $21.0 \%$ & $1.0 \%$ & $100.0 \%$ \\
\hline & & $\%$ de logro & $100.0 \%$ & $100.0 \%$ & $100.0 \%$ & $100.0 \%$ & $100.0 \%$ \\
\hline & & $\%$ del total & $5.5 \%$ & $72.4 \%$ & $21.0 \%$ & $1.0 \%$ & $100.0 \%$ \\
\hline
\end{tabular}

$\mathrm{X}^{2}=28.328 ; \mathrm{gl}=12 ; \mathrm{p}<0.004$

En la Tabla 8 se aprecia el cruce del estado civil de los padres y el nivel global de logro de los estudiantes. En el nivel sobresaliente (AD) se ubican, en primer lugar, los hijos de padres casados (7\%), luego los hijos de padres viudos (6.7\%), los hijos de padres convivientes (5.6\%) y separados ( $2 \%)$. En el nivel de logro obtenido (A) están primero los hijos de padres casados 
(77.3\%), y después siguen los hijos de padres divorciados (76.5\%), de padres convivientes (70 \%), de padres viudos (66.7\%) y de padres separados (36.6\%). En el nivel de logro de aprendizaje en proceso (B), se tiene: $33.1 \%$ de hijos de padres separados, $26.7 \%$ de hijos de padres viudos, $23.5 \%$ de hijos de padres divorciados, y en igual medida de padres convivientes, y $14.7 \%$ de hijos de padres casados. Finalmente, en el nivel de logro deficiente (C) se ubican los hijos de padres separados (1.3\%), casados (1\%) y convivientes (0.9 \%). Estos resultados fueron muy significativos $(\mathrm{p}<0.004)$.

Tabla 9.

Tabla de contingencia tipo de familia * nivel de logro en comunicación integral

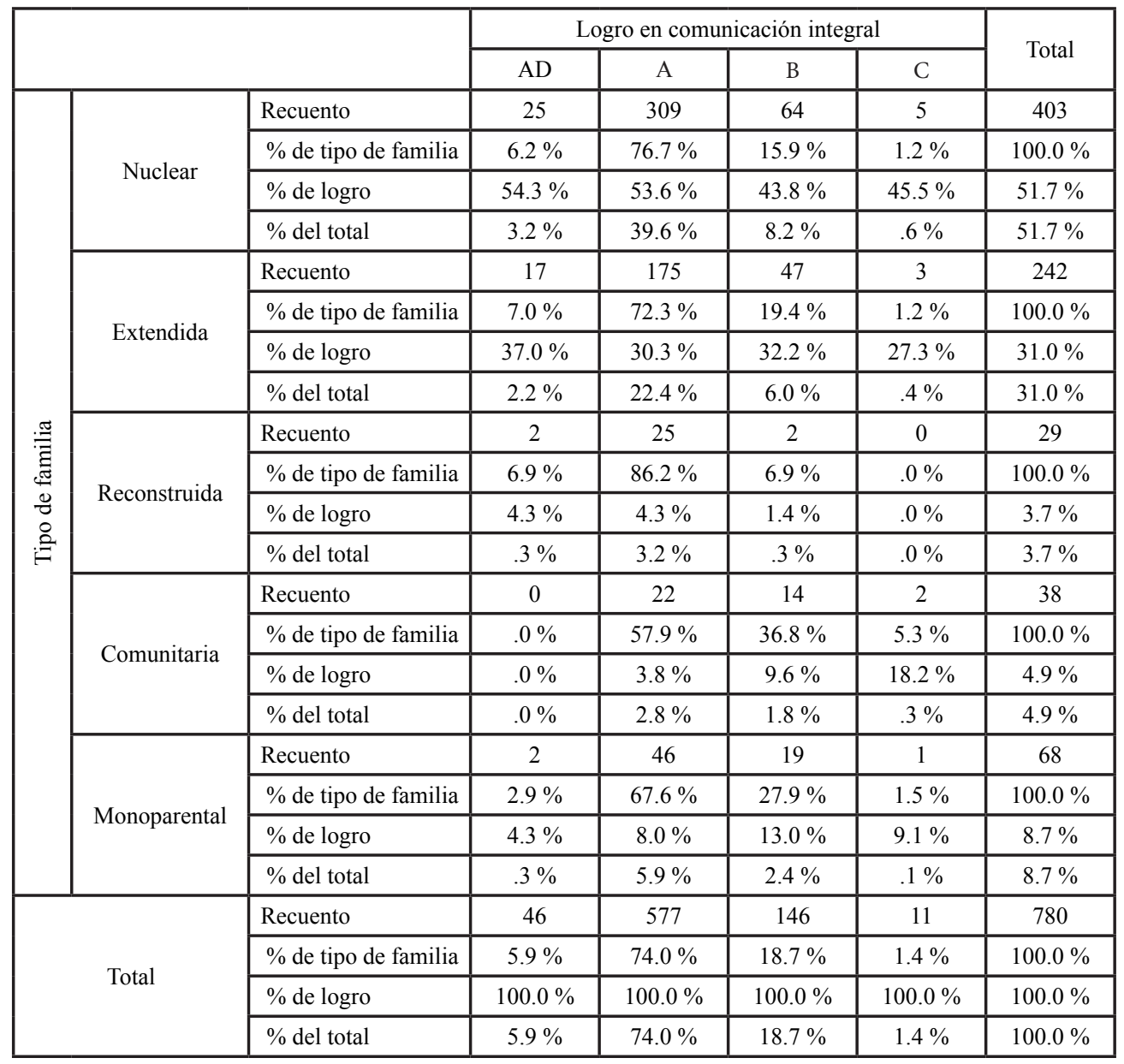

$\mathrm{X}^{2}=24.917 ; \mathrm{gl}=12 ; \mathrm{p}<0.015$

En la Tabla 9 se tiene la distribución porcentual en función del tipo de familia y el nivel de logro en el área de comunicación integral. Tenemos que el 5.2 \% de estudiantes con nivel de logro AD provienen de hogares nucleares, y le siguen en orden descendente quienes 
provienen de familias extendidas (5\%) y monoparentales (4.4\%). En el nivel de logro A se ubican primero los estudiantes de familias reconstruidas (89.7\%), y luego están las familias nucleares (72.7\%), extendidas (68.6\%), comunitarias (63.2 \%) y las monoparentales $(61.8 \%)$. En el nivel B, el orden se da como sigue: monoparental (33.8\%), comunitaria (31.6\%), extendida $(24.4 \%)$, nuclear $(20.8 \%)$ y reconstruida (10.3\%). Finalmente, en el nivel de logro C, se tiene: comunitaria (5.3\%), extendida (2.1\%) y nuclear (1.2\%). Estos resultados no fueron tan significativos como en los casos anteriores $(\mathrm{p}<0.074)$.

\section{Tabla 10.}

Tabla de contingencia tipo de familia * nivel de logro en lógico matemática

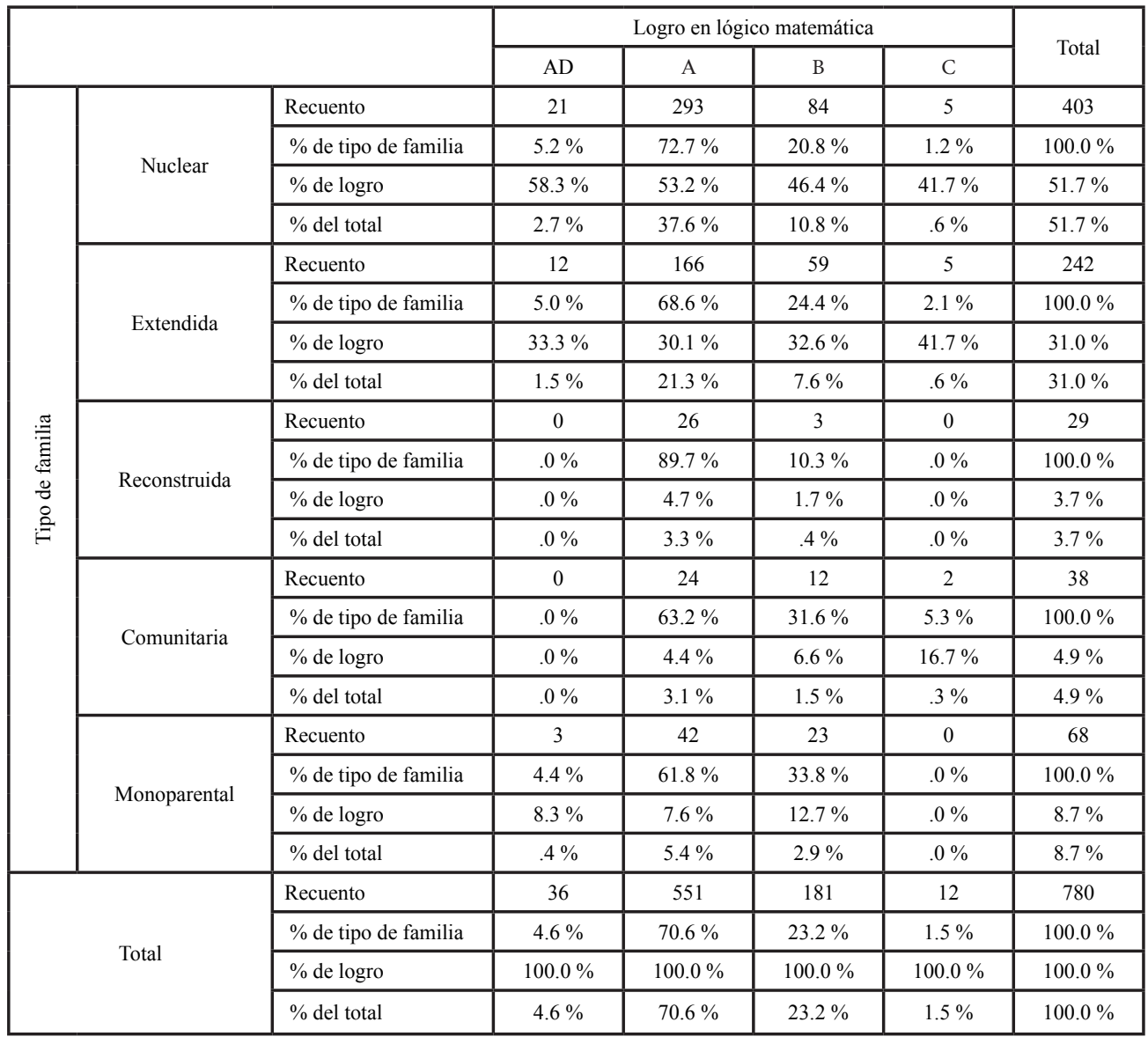

$\mathrm{X}^{2}=19.620 ; \mathrm{gl}=12 ; \mathrm{p}<0.074$

En la Tabla 10 se tiene el cruce de datos entre el tipo de familia y el nivel de logro en el área lógico matemática. Como se puede apreciar, el 5.2 \% de estudiantes que provienen de familias nucleares alcanza una valoración de AD y le siguen el $5 \%$ de estudiantes de familias exten- 
didas, el $4.4 \%$ de familias monoparentales. En el calificativo A se tiene el siguiente orden: 89.7 \% de estudiantes de familias reconstruidas, $72.7 \%$ de familias nucleares, $68.6 \%$ de familias extendidas, $63.2 \%$ de familias comunitarias y el $61.8 \%$ de familias monoparentales. En el nivel de logro B, se tiene que el $33.8 \%$ proviene de familias monoparentales, $31.6 \%$, de familias comunitarias, $\mathbf{2 4 . 4} \%$, de familias extendidas, $20.8 \%$, de familias nucleares y $10.3 \%$, de familias reconstruidas. En el nivel de logro más bajo, se tiene que el 5.3 \% proviene de familias comunitarias, $\mathbf{2 . 1} \%$, de familias extendidas y $1.2 \%$, de familias nucleares. Estos datos casi alcanzan el nivel de significación estadística óptimo ( $\mathrm{p}<0.074)$.

Tabla 11.

Tabla de contingencia tipo de familia * nivel de logro global

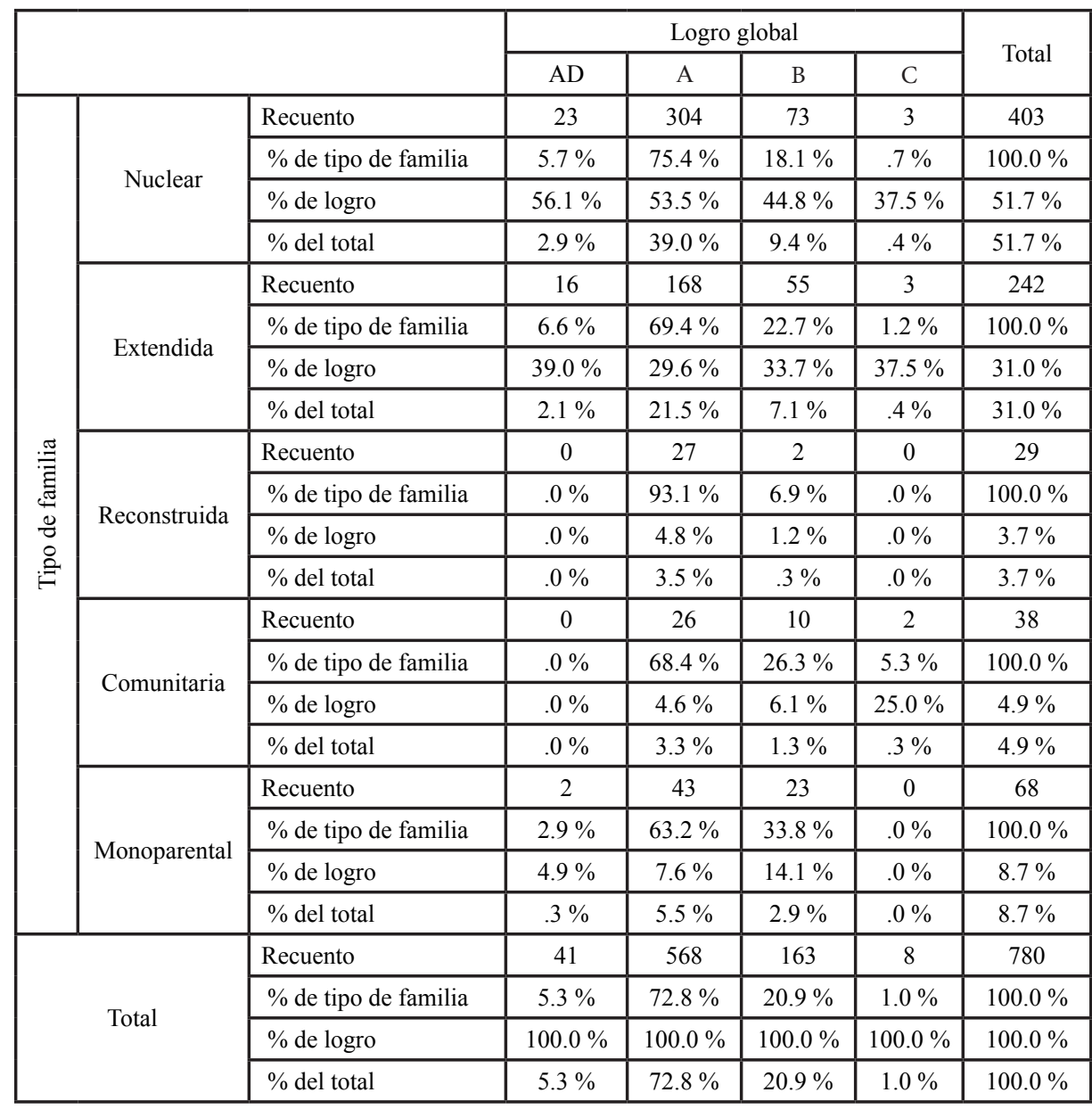

$\mathrm{X}^{2}=27.215 ; \mathrm{gl}=12 ; \mathrm{p}<0.007$

Finalmente, tenemos que, a nivel global, el $6.6 \%$ de estudiantes de familias extendidas tienen un nivel de logro sobresaliente (AD), el 5.77\% de estudiantes de familias nucleares, 
así como el $2.9 \%$ de estudiantes de familias monoparentales. Con un nivel de logro en la categoría A, se tiene que $93.1 \%$ de estudiantes de familias reconstruidas, el $75.4 \%$ de familias nucleares, $69.4 \%$ de familias extendidas, el $68.4 \%$ de familias comunitarias y el $63.2 \%$ de familias monoparentales se ubican en este nivel. En la categoría B se tienen los siguientes porcentajes de estudiantes según el tipo de familia de la que provienen: $33.8 \%$, monoparentales, $26.3 \%$, comunitarias, $22.7 \%$, extendidas, $18.1 \%$, nucleares, y $6.9 \%$, reconstruidas. Para terminar, el 5.3\% de familias comunitarias tienen hijos con un nivel de aprendizaje deficiente, y le siguen las familias extendidas con $1.2 \%$ y las familias nucleares con $0.7 \%$ (ver Tabla 11). Los resultados fueron altamente significativos $(\mathrm{p}<0.007)$.

\section{Discusión}

El rendimiento escolar es un tema que preocupa a muchos investigadores del ámbito educativo, pues los índices de aprovechamiento escolar en nuestro país son muy bajos. En las pruebas PISA hemos ocupado los últimos lugares en comprensión lectura y matemática, en las dos evaluaciones efectuadas en el 2001 y el 2009 (Sotelo, Sotelo, Sotelo, Matalinares, Arenas \& Caycho, 2012). Los estudios que se han efectuado sobre el rendimiento escolar en el Perú aportan información relevante que nos bosqueja una realidad plagada de desigualdades. Por ejemplo, los niños de zonas rurales tienen un rendimiento escolar inferior al de los niños de zonas urbanas (Cueto, Jacoby \& Pollitt, 1997). De hecho las tasas de analfabetismo son superiores en las zonas rurales y amazónicas que en las ciudades, además de que un mayor porcentaje de mujeres es analfabeta en comparación con los varones (Aranzamendi, 2008). El atraso escolar también es una variable que, como el analfabetismo, está todavía presente en la sociedad peruana: el $46 \%$ de la población tiene problemas de atraso escolar, de los cuales, el $69 \%$ son quechua hablantes, el 56 \% viven en la Amazonía y el 54 \% vive en zonas rurales (Beltrán, 2013).

También se ha reportado que los niños que han cursado educación inicial tienen mejor rendimiento en la primaria que aquellos que no han seguido este ciclo de estudios (Cueto \& Díaz, 1999). Otras variables que también se han estudiado, relativas a la escuela, son las horas de estudio en el aula, de modo que la asistencia de los profesores es un fuerte predictor del rendimiento escolar (Cueto, Torero, León \& Deustua, 20o8). Sin embargo, la realidad es que los alumnos peruanos de escuelas públicas estudian menos horas de las que se programan a nivel escolar, con índices de horas de estudio en la escuela por debajo de países como Brasil, Chile y Colombia, donde se trabajan 40 semanas de clase, mientras que en el Perú se llega a 22, en lugar de las 36 programadas (Aranzamendi, 2008). Esto podría explicarse por el desinterés que exhiben hacia el alumno los profesores de escuelas públicas, ya que en un estudio previo reportamos que en las escuelas de gestión estatal, los índices de despersonalización de los profesores eran mayores que el de sus pares de escuelas privadas. Esto significa que los docentes de escuelas públicas son más distantes de los alumnos y se comprometen menos con su aprovechamiento 
escolar, posiblemente, como una manera de protegerse frente al estrés crónico laboral propio del contexto escolar (Arias \& Jiménez, 2013).

En ese sentido, no podemos olvidar que las experiencias en la escuela deben potenciar el desarrollo de las capacidades de aprendizaje de los alumnos, de modo que el éxito escolar garantice su adecuado desenvolvimiento en la sociedad a través del uso de diversas herramientas culturales mediadas por los procesos de enseñanza-aprendizaje que tienen lugar en la escuela. Por ello, sea que el alumno tenga éxito o que fracase en el colegio, el profesor debe concentrarse en el mejoramiento de sus conocimientos, habilidades y valores, propiciando su paulatino progreso. Esto supone reconocer su esfuerzo, darle oportunidades de mejora y estimular la visión de que los errores son parte del proceso de aprendizaje (Moreno, 2009). Por otro lado, el desempeño escolar descansa, en buena medida, en el quehacer de los padres, quienes desde el hogar monitorean el desenvolvimiento de sus hijos, brindándoles modelos de conducta adecuados, estimulando su interés por el aprendizaje y facilitándoles herramientas de estudio.

Por esta razón, la escuela no debe concebirse de manera aislada, sino, más bien, en estrecha relación con la familia, de modo que entre ambas instituciones se promuevan lazos de cooperación hasta conformar redes vinculares que brinden el soporte adecuado a los estudiantes (Dabas, 1998). Lamentablemente, esto no ocurre, tal es así que muy poco se han investigado en nuestro medio local las relaciones entre la familia y la escuela. A nivel nacional, empero, son varias las investigaciones que se avocan a este tema, pues desde hace varias décadas se han venido analizando los efectos de la familia en la educación y el rendimiento escolar de los niños y jóvenes (Pinzas, 1987; Burgos, 2004).

En ese aspecto, autores como L. Arias (2013) señalan que el rendimiento escolar es producto de la interacción entre los recursos que aportan tanto la familia como la escuela. En el estudio de Beltrán (2013), por ejemplo, se encontró que la condición laboral de los padres afecta el desarrollo cognitivo de los niños y que mientras más tiempo dedican al trabajo, menor es el logro educativo de sus hijos. También se encontró que mayor es la atención que brindan los padres a los logros escolares cuando sus hijos están en inicial y primaria, precisamente por ello, el presente estudio se enmarca en el nivel educativo primario, ya que, a nivel secundario, los efectos de la familia en la escuela decrecen (Arias L., 2013).

Nuestro trabajo de investigación analiza las relaciones entre la estructura familiar y el nivel de logro en una muestra de estudiantes de escuelas públicas de nivel primario de la ciudad de Arequipa. En ese sentido, se han reportado diversos beneficios de las estructuras familiares nucleares por sobre las otras estructuras familiares (familias extendidas, reconstruidas y monoparentales) a nivel social, económico y psicológico. En el plano social, se tiene que las familias nucleares representan un modelo más estable para promover la socialización a través de la delimitación más clara de los roles y responsabilidades familiares (Minuchin \& Fishman, 1996), tomando en consideración el ciclo vital en el que se encuentre la familia 
(Ríos, 2005). A nivel económico, varios estudios en el Perú dan cuenta de que las estructuras familiares nucleares hacen un gasto y distribución más eficiente de los ingresos económicos si se les compara con las familias reconstruidas y las monoparentales (Castro, 2015; Riesco \& Arela, 2015). Psicológicamente, las familias nucleares tienen menos conflictos intrafamiliares o interfamiliares, aunque esto también depende del orden que se imponga en cada holón familiar, según la estructura familiar (Arias, 2012). Algunos estudios recientes también aportan información al señalar que las familias nucleares presentan mayor nivel de bienestar entre sus miembros (Alarcón, 2014; Arias, Masías, Salas, Yepez \& Justo, 2014).

En cuanto a nuestros hallazgos, un primer dato que merece atención es que las estudiantes mujeres tienen padres casados en un 66.3\%, en comparación con los varones, que solo los tienen en un $40.8 \%$. Asimismo, el $55.5 \%$ de las mujeres provienen de familias nucleares, mientras que esto ocurre en el $50 \%$ de los varones. En ambos casos los valores son altamente significativos $(\mathrm{p}<0.006)$. Pareciera que cuando hay hijas mujeres en las familias, estas tienden a integrarse más, posiblemente porque la prole de sexo femenino requiere de más cuidados que los varones, por los riesgos que supone tener hijas mujeres en hogares monoparentales o en familias reconstruidas, pues las cifras de violencia y acoso sexual son mayores en este tipo de estructuras familiares que en las familias nucleares (Instituto Nacional de Estadística e Informática [INEI], 2014), ya que los lazos de consanguinidad entre padres e hijas reducen la posibilidad de contacto físico entre ellos.

Con respecto al nivel de logro según el sexo, se encontró que las estudiantes mujeres presentan un mejor rendimiento que los varones en el área de comunicación integral, mientras que estos presentan un mejor rendimiento en el área lógico matemática, aunque estas diferencias no fueron tan significativas en el segundo caso. Este hallazgo refuerza los reportes en varios estudios, donde se indica que los varones presentan mejor rendimiento en matemática que las mujeres (León, 2013; Bravo, 2014), debido a las asimetrías cerebrales que se observan entre ambos sexos (Bravo, 1995; Calvo, 2008; Salas, 2008; Ortiz, 2011), y que se encuentran también mediadas por las patrones diferenciados de socialización que impactan en el desarrollo de su personalidad (De Fruyt, Van Leeuwen, De Bolle \& De Clercq, 2008). Además, las mujeres tuvieron un nivel de logro mayor que el de los varones en la valoración global, lo que se explica por el hecho de que estas son más disciplinadas para el estudio (Gordillo, Rivera-Calcina \& Gamero, 2014), tienen mayor motivación de logro (Thornberry, 2003) y su autoconcepto académico está mejor definido (Moreano, 2005). Estas diferencias en el comportamiento orientado hacia metas académicas que aventaja a las mujeres han sido explicadas por León (2012) desde un enfoque bio-psico-geográfico, que plantea que el sexo femenino tiende a ser más dominante a medida que se ubica hacia una latitud norte sur (en la ubicación geográfica del Perú), por ende, las mujeres que viven más cerca del trópico serán más sumisas que las que viven hacia el polo sur. Esta sumisión se traduce en menos expectativas de poder doméstico, menor grado de instrucción, menor rendimiento 
escolar, menor productividad y más riesgo de ser víctima de violencia intrafamiliar, de padecer problemas de salud mental y de consumo de sustancias psicoactivas.

Por otro lado, tenemos que el estado civil de los padres se relaciona con un nivel de logro sobresaliente en el área de comunicación integral, pues los hijos de padres casados y convivientes alcanzaron porcentajes del 7.7 \% y el $5.6 \%$, respectivamente, en el calificativo AD; mientras que, en un nivel de logro adecuado (A), los hijos de padres casados, divorciados y convivientes se ubican con los porcentajes más altos de representación. En un nivel de logro inferior, se ubican mayoritariamente los estudiantes cuyos padres están separados o divorciados. Aunque estos datos casi alcanzan la significancia estadística ( $\mathrm{p}<0.051)$, nos indican que las estructuras familiares nucleares están asociadas con un mejor aprendizaje de los estudiantes, mientras que los que provienen de hogares desintegrados presentan más problemas de estudio (Bengoechea, 1992). Esto se ratifica cuando vemos que los estudiantes que provienen de familias nucleares también alcanzan un mayor nivel de logro en comunicación integral, seguidos de las familias extendidas y las monoparentales. Las familias nucleares, reconstruidas y extendidas son, según nuestros resultados, las estructuras familiares más eficientes en la promoción del aprovechamiento escolar en el área de comunicación integral. Es importante notar que esta área de estudio se vincula mucho con la lectura, en ese sentido, un estudio hecho por De Baessa y Fernández (2003) concluyó que las cuatro variables familiares que más se asocian con el rendimiento de la lectura son el nivel educativo de la madre, la cantidad de libros en el hogar, el que el padre lea el periódico y ver televisión en casa.

Para el caso del nivel de logro en el área lógico matemática, se tiene que los hijos de padres viudos, convivientes y casados tienen las notas más sobresalientes, mientras que un nivel óptimo de logro lo alcanzan los estudiantes cuyos padres son casados, convivientes y divorciados, con un nivel de significancia alta $(\mathrm{p}<0.002)$. Aquí también tenemos que los estudiantes que provienen de hogares nucleares, de familias extendidas y monoparentales tienen un nivel sobresaliente; mientras que las familias reconstruidas, nucleares y extendidas abarcan mayor porcentaje del logro de los estudiantes en el nivel de la categoría A, pero estos valores no fueron tan significativos ( $<<0.074)$. En el nivel de logro global se tiene que los padres casados, viudos y convivientes se ubican en el nivel sobresaliente, mientras que, en el nivel óptimo, se ubican los padres con estado civil casado, divorciado y conviviente. El tipo de familia extendida, nuclear y monoparental se asocia con el nivel de logro sobresaliente, al igual que las familias reconstruidas, nucleares y extendidas se asocian con el nivel de logro óptimo. En ambos casos se hallaron asociaciones estadísticamente significativas: $\mathrm{p}<0.004$ y $\mathrm{p}<0.007$, respectivamente.

De todos estos datos, podemos concluir que las familias que se asocian con un mejor nivel de logro de los estudiantes de colegios públicos de la ciudad de Arequipa de nivel primario son las que poseen una estructura familiar, nuclear, extendida o reconstruida. 
Aunque otros estudios no han reportado una relación significativa entre el tipo de familia y el rendimiento del alumno (Sotil, 2002), en nuestra investigación parece evidenciarse que, cuando las familias son nucleares, extendidas y reconstruidas, sus miembros hacen un acompañamiento académico eficiente de los integrantes de la familia en edad escolar. Esta atención prestada al escolar se hace más necesaria cuando está en los niveles de educación inicial y primaria, asimismo, leer y hacer las tareas con los hijos en la casa, han sido actividades que se asocian con mayores niveles de desempeño académico (Beltrán, 2013). Si bien no hemos evaluado el nivel educativo de los padres, se sabe que esta variable es un fuerte predictor del desempeño escolar de los hijos, sobre todo si la madre tiene un nivel de instrucción superior o de postgrado (Estrella, 1996). También media el nivel socioeconómico de los padres, que se asocia con el desarrollo cognitivo de los estudiantes (Bravo, 1993) y con la integración familiar (Castro et al., 2013).

De acuerdo con esto, en las estructuras familiares donde dos o más adultos están presentes, sea que se trate de padres biológicos (familias nucleares), de familiares en primer y/o segundo grado (familias extendidas) o de padrastros (familias reconstruidas), se brinda aparentemente un mejor apoyo y acompañamiento de las responsabilidades escolares, si nos basamos en el nivel de logro que alcanzan los alumnos en comunicación integral, lógico matemática y a nivel global. En cuanto a las familias nucleares, no en todos los casos se asocian con un mayor porcentaje del nivel de logro, aunque sí ocurre en la mayoría de análisis efectuados. Esto puede deberse a que posiblemente no haya un ambiente familiar adecuado, pues una familia nuclear no siempre garantiza el óptimo ajuste de los hijos durante la etapa escolar, más aún si se trata de hogares con un nivel socioeconómico medio bajo o bajo, como podría ocurrir en el contexto escolar de las escuelas públicas peruanas. Por ejemplo, entre los factores de riesgo de los hogares de bajos recursos que contribuyen al fracaso escolar se tienen el ambiente familiar conflictivo, hacinamiento, el ruido, la escasez o ausencia de materiales de apoyo para el estudio, la baja escolaridad de los padres, la ausencia de estos, la escasa interacción madre-hijo y las bajas expectativas de los padres sobre el futuro académico de los hijos (Jadué, 1996).

Por ello, es importante fortalecer la estructura familiar a través de políticas y medidas socioeconómicas que distribuyan la riqueza de manera más equitativa entre la población, para que las familias puedan cubrir las necesidades propias de los tiempos que nos tocan vivir, con comodidades materiales y sueldos que permitan cubrir los gastos de la canasta familiar, con acceso a la tecnología y la cultura, etc. Además, es necesario formular políticas laborales que atiendan el conflicto trabajo-familia, para que las funciones familiares no se opongan a las demandas laborales. De este modo, los trabajadores tendrían mayores facilidades para pasar tiempo con la familia y asumir mejor las funciones de orientación y monitoreo del quehacer académico de los hijos 
en edad escolar. Así también, es importante promover una cultura familiar orientada por el amor conyugal, paternal-maternal y fraternal (Melina, 2010).

En el caso de las familias extendidas, que ocupan un porcentaje importante en los niveles de logro sobresaliente y óptimo, se ha demostrado que es posible que los abuelos construyan vínculos afectivos sólidos con sus nietos, lo cual se dejaría ver en las interacciones afectivas con los nietos y la asunción de responsabilidades parentales por parte de los abuelos, como el apoyo que le dan a sus hijos cuando estos enfrentan tempranamente la labor de ser padres (Portilla, Zapana \& Vilches, 2012). En esos casos, la familia extendida es un soporte muy importante para favorecer el desarrollo físico y mental de los miembros más pequeños. Los abuelos pueden $-\mathrm{y}$ de hecho lo hacen-asumir las funciones de tutores de los deberes escolares de los nietos, cuando los padres, por distintos motivos, no pueden hacerlo. Ello obviamente requiere de cierto nivel cultural de los abuelos, pero sin que ello implique suplir de manera permanente las responsabilidades formativas de los padres para con los hijos.

Por otro lado, ante los cambios que se vivencian en las estructuras familiares (véase Perriaux, 2011), las familias reconstruidas también parecen asumir de manera adecuada las funciones educativas y de apoyo que la escuela requiere. Esto parece relacionarse con el hecho de que, en estas familias, los cónyuges que las conforman cuentan con experiencia que puede reducir los errores cometidos en relaciones pasadas, aportando más a la armonía familiar y a la asunción más responsable de las funciones familiares, incluyendo las de orden escolar. Hay que reconocer también que son múltiples los motivos por los que las personas forman familias reconstruidas, y que estos podrían tener un efecto mediador en la eficacia con la que se conducen de manera cotidiana, y más específicamente, con respecto al acompañamiento de las obligaciones escolares que se ejerce desde casa.

Las familias monoparentales que se asocian con el estado civil de viudo, separado y divorciado de los padres son las que han resultado menos efectivas a la hora de promover el desempeño escolar de los hijos, posiblemente porque la carga familiar se torna mayor ante la ausencia de uno de los padres. Pero también se debe recalcar que el hecho de provenir de una familia monoparental no es un factor determinante del fracaso escolar (Oporto \& Zanabria, 2006). También hay que tomar en consideración que son muchos los motivos por los cuales existen las familias monoparentales, de hecho, hoy en día, la monoparentalidad electiva de parte de las mujeres va en aumento, y no responde a las causas tradicionales de separación, divorcio o viudez, sino al proyecto de vida asumido por una mujer que desea ser madre sin contar con una pareja estable o una figura paterna a su lado (Salvo \& Gonzálvez, 2015). Esta realidad se está haciendo cada vez más frecuente en nuestro medio y merece ser atendida desde diversos ángulos, teniendo siempre como premisa el bienestar de los hijos. 
Para terminar, solo queremos mencionar algunas limitaciones en el presente trabajo que deberán ser superadas en futuras investigaciones. Primero, deben considerarse muestras de escolares de instituciones educativas privadas, aunque el acceso a escuelas de este tipo de gestión es muy difícil. En segundo lugar, debe afinarse más el instrumento de recolección de datos para no dejar de lado información como los motivos del estado civil de los padres, el nivel de logro en otras áreas curriculares como en ciencia y ambiente, personal social, etc. En tercer lugar, ayudaría mucho contar con datos cuantitativos para realizar procesamientos estadísticos más complejos, como análisis de correlación, factoriales o de regresión. Finalmente, este estudio centra su atención en un tema que muchas veces es descuidado por los investigadores locales y nacionales, como es el de las relaciones sinérgicas que pueden establecerse entre la familia y la escuela, para el bienestar de los estudiantes. Consideramos por ello que, a pesar de las limitaciones, el tema tratado es original y requiere de mayor profundización como línea de investigación regional por parte de los especialistas en temas de familia.

\section{Referencias}

Alarcón, R. (2014). Funcionamiento familiar y sus relaciones con la felicidad. Revista Peruana de Psicología y Trabajo Social, 3(1), 61-74.

Alegre, A. A. (2013). Ansiedad ante los exámenes y estrategias de aprendizaje en estudiantes de secundaria de Lima Metropolitana. Propósitos y Representaciones, 1(1), 107-130.

Aranzamendi, L. (2008). Crisis universitaria. Arequipa: ADRUS.

Arias, L. (2013). Caracterización del desempeño académico del escolar en ausencia de al menos uno de sus padres. Aproximación desde el caso Milagro. Educación, $22(43), 27-50$.

Arias, W. L. (2012). Algunas consideraciones sobre la familia y la crianza desde un enfoque sistémico. Revista de Psicología de Arequipa, 2(1), 32-46.

Arias, W. L. (2013). Agresión y violencia en la adolescencia: La importancia de la familia. Avances en Psicología, 21(1), 23-34.

Arias, W. L., \& Jiménez, N. A. (2013). Síndrome de burnout en docentes de educación básica regular de Arequipa. Educación, 22(42), 53-76.

Arias, W. L., Masías, M. A., Salas, X., Yepez, L., \& Justo, O. (2014). Integración familiar y felicidad en la ciudad de Arequipa. Revista de Psicología de Arequipa, 4(2), 189-199.

Arias, W. L., Sancho, L., Lévano, N., \& Collado, B. (2014). Relación entre el estado nutricional y la memoria de trabajo en escolares. Revista Peruana de Psicología y Trabajo Social, 3(1), 91-106.

Baessa, Y. de, \& Fernández, F. J. (2003). Factores del hogar en el rendimiento escolar. Revista de Psicología de la PUCP, 21(2), 311-331.

Beltrán, A. (2013). El tiempo de la familia es un recurso escaso: ¿cómo afecta su distribución en el desempeño escolar? Apuntes, 40(72), 117-156. 
Bengoechea, P. (1992). Un análisis exploratorio de los posibles efectos del divorcio en los hijos. Psicothema, 4(2), 491-511.

Bocanegra, B. (2009). Evaluación del aprendizaje. Lambayeque: UPRG.

Bravo, L. (1993). Retardo mental sociocultural o diferencias cognitivas en niños de nivel socioeconómico bajo. Revista de Psicología de la PUCP, 11(1), 45-66.

Bravo, L. (1995). Lenguaje y dislexias. Enfoque cognitivo del rendimiento lector. Santiago: Ediciones Universidad Católica de Chile.

Bravo, L. (2014). Psicología cognitiva y neurociencias de la educación en el aprendizaje del lenguaje escrito de las matemáticas. Revista de Investigación en Psicología, $17(2), 25-37$.

Burgos, J. M. (2004). Diagnóstico sobre la familia. Madrid: Biblioteca Palabra.

Caffarra, C. (2011). La familia: Un lugar de la experiencia de comunión. Persona y Cultura. 9, 69-79.

Calvo, M. (2008). Hombres y mujeres: Cerebros y educación. Las diferencias cerebrales entre los sexos y su importancia en el aprendizaje. España: Almuzara.

Castro, R. (2015). Familia, economía y bien común: Efectos de la transición demográfica. Un acercamiento desde las ciencias sociales. Kénosis, 3(4), 78-95.

Castro, R., Arias, W. L., Dominguez, S., Masías, M. A.; Salas, X.; Canales, F., \& Flores, A. (2013). Integración familiar y variables socioeconómicas en Arequipa metropolitana. Revista de Investigación de la UCSP, 4, 35-65.

Condemarín, M., \& Scagliotti, J. (1979). Repitencia escolar: Un análisis de regresión múltiple. Revista Latinoamericana de Psicología, 11(2), 205-217.

Cueto, S., \& Díaz, J. J. (1999). Impacto de la educación inicial en el rendimiento en primer grado de primaria en escuelas públicas urbanas de Lima. Revista de Psicología de la PUCP, 17(1), 73-91.

Cueto, S., Jacoby, E., \& Pollitt, E. (1997). Rendimiento de niños y niñas de zonas rurales y urbanas del Perú. Revista de Psicología de la PUCP, 15(1), 115-133.

Cueto, S., Torero, M., León, J., \& Deustua, J. (2008). Asistencia docente y rendimiento escolar, Documento de Trabajo 53. Lima: GRADE.

Cuevas, A. (2005). Rendimiento escolar y estructuración curricular en la educación básica. Revista Cubana de Psicología, 22(1), 28-32.

Dabas, E. (1998). Redes sociales, familias y escuelas. Buenos Aires: Paidós.

De Fruyt, F., Van Leeuwen, K., De Bolle, M., \& De Clercq, B. (20o8). Sex differences in school performance as a function on conscientiousness, imagination and the mediating role of problem behavior. European Journal of Personality, 22, 167-184.

Escudero, J. M. (2005). Fracaso escolar, exclusión educativa: ¿De qué se excluye y cómo? Profesorado. Revista de Curriculum y Formación del Profesorado, 1(1), 1-24. 
Espinoza, E. (2009). Impacto del maltrato en el rendimiento académico. Revista Electrónica de Investigación Educativa, 9(4), 221-238.

Estrella, C. (1986). Actitudes maternas y nivel socioeconómico: Un estudio comparativo. Revista de Psicología de la PUCP, 4(1), 37-59.

Frías, M., Corral, V., López, A., Díaz, S., \& Peña, E. (2001). Predictores familiares y conductuales de la problemática escolar en alumnos de secundaria y preparatoria. Revista de Psicología de la PUCP, 19(2), 237-256.

Frías, M., Rodríguez, I., \& Gaxiola, J. (2003). Efectos conductuales y sociales de la violencia familiar en niños mexicanos. Revista de Psicología de la PUCP, 21(1), 41-69.

García-Zapatero, G. (1983). Ansiedad debilitadora y rendimiento escolar. Revista de Psicología de la PUCP, 1(1), 61-65.

Garrido Lecca, M. de (1997). Autoestima en adolescentes con bajo rendimiento escolar a través del psicodiagnóstico de Rorschach. Revista de Psicología de la PUCP, 15(2), 179-199.

Garrido Lecca, M. de., \& Figueroa, M. (1992). Dificultades en el proceso de identificación y bajo rendimiento escolar visto a través del psicodiagnóstico de Rorschach. Revista de Psicología de la PUCP, 10(1-2), 41-64.

Gaxiola, J., González, S., Contreras, Z., \& Gaxiola, E. (2012). Predictores del rendimiento académico en adolescentes con disposiciones resilientes y no resilientes. Revista de Psicología de la PUCP, 3o(1), 47-74.

Good, T. L., \& Brophy, J. (1999). Psicología educativa contemporánea. México: McGraw-Hill. Gordillo, E.; Rivera-Calcina, R., \& Gamero, G. J. (2014). Conductas disruptivas en estudiantes de escuelas diferenciadas, coeducativas e interducativas. Educación E Educadores, 17(3), 427-443.

Guerra, R. (2004). ¿Familia o familias? Familia natural y funcionalidad social. Persona y Cultura. 3, 87-103.

Hellinger, B. (2005). Órdenes de amor. Barcelona: Herder.

Instituto Nacional de Estadística e Informática (2014). Encuesta demográfica de salud familiar-ENDES. Lima: INEI.

Jadué, G. (1996). Características familiares de los hogares pobres que contribuyen al bajo rendimiento o al fracaso escolar de los niños. Revista de Psicología de la PUCP, $14(1), 35-45$.

Jadué, G. (2000). Algunas características familiares y de la escuela que contribuyen a la etiología de la tensión emocional. Revista de Psicología de la PUCP, 18(1), 69-85.

Jadué, G. (2003). Transformaciones familiares: desafío para la educación del siglo XXI. Revista de Psicología de la PUCP, 21(2), 271-289.

León, F. (2012). The latitudinal tilts of wealth and education in Peru: Testing them, explaning them and reflecting on them. Economía, 35(70), 60-102. 
León, F. (2013). Diferencias de sexo en matemática y comprensión lectora según el poder femenino, urbanización y habilidad. Propósitos y Representaciones, 1(1), 11-37.

Majluf, A. (1993). Marginalidad, inteligencia y rendimiento escolar. Lima: Editorial Brandon Enterprise S.R.L.

Melina, L. (2010). Por una cultura de la familia. El lenguaje del amor. Arequipa: Universidad Católica San Pablo.

Miljánovich, M., Quesada, F., Atalaya, M., Huerta, R., Aliaga, J., \& Evangelista, D. (2005). Relación entre habilidades de procesamiento de la información y rendimiento académico. Revista de Investigación en Psicología, 8(2), 13-21.

Minuchin, S. (2003). El arte de la terapia familiar. Barcelona: Paidós.

Minuchin, S., \& Fishman, H. (1996). Técnicas de terapia familiar. México: Paidós.

Moreano, G. (2005). Relaciones entre autoconcepto académico, atribuciones de éxito y fracaso, y rendimiento académico en escolares. Revista de Psicología de la PUCP, 23(1), 5-38.

Moreno, M. (2009). ¿Por qué aprenden los estudiantes? Los objetivos de logro y su relación con el éxito o fracaso escolar. Zona Próxima, 11, 184-195.

Navarro, R. E. (2003). Factores asociados al rendimiento académico. Revista Iberoamericana de Educación, 20(9), 1-20. Descargado de: www.rieoei.org/investigacionı.htm

Oporto, C., \& Zanabria, L. (2006). Inteligencia emocional en hijos de familias nucleares y monoparentales. Revista de Psicología de la UCSM, 3, 25-36.

Ortiz, T. (2011). Neurociencia y educación. Madrid: Alianza.

Perriaux, J. (2011). La familia ante algunos desafíos de la realidad actual. Persona y Cultura. 9, 12-33.

Pinzas, J. (1987). Notas para una propuesta sobre las relaciones entre familia y educación. Rol de los padres en el aprendizaje de la lectura y la comprensión lectora. Revista de Psicología de la PUCP, 5(2), 177-188.

Pollitt, E. (2002). Consecuencias de la desnutrición en el escolar peruano. Lima: PUCP.

Portilla, Ch., Romero, B., \& Gonzales, J. (2008). Apego infantil en madres que trabajan y no trabajan. Revista de Psicología de la UCSM, 5, 5-21.

Portilla, Ch.; Zapana, F., \& Vilches, F. (2012). Apego de niños hacia abuelas y madres estudiantes de educación superior. Revista de Psicología de la UCSM, 9, 5-32.

Riesco, R., \& Arela, R. (2015). Impacto de la estructura familiar en la satisfacción con los ingresos en los hogares urbanos en Perú. Economía, 38(76), 51-76.

Ríos, J. A. (2005). Ciclos vitales de la familia y pareja: ¿Crisis u oportunidades? Madrid: Editorial CCS.

Rodríguez, P. J. (2003). Estudio de la asociación entre trastornos psiquiátricos y rendimiento escolar en una muestra de niños canarios. Revista Canaria de Pediatría, 27(3), 389-396.

Salas, R. E. (2008). Estilos de aprendizaje a la luz de la neurociencia. Bogotá. Magisterio. 
Salvo, I., \& Gonzálvez, H. (2015). Monoparentalidades electivas en Chile: Emergencias, tensiones y perspectivas. Psicoperspectivas, 14(2), 40-50.

Soriano, E. (2008). Dificultades socio-emocionales del alumno con altas habilidades. Revista de Psicología de la PUCP, 26(1), 43-62.

Sotelo, L., Sotelo, N., Sotelo, C., Matalinares, M. L., Arenas, C., \& Caycho, T. (2012). Efectos de un programa experimental interactivo para mejorar la comprensión lectora de una población rural de 5 to grado de educación primaria. Revista de Investigación en Psicología, 15(1), 93-107.

Sotil, A. (2002). Influencias del clima familiar, estrategias de aprendizaje e inteligencia emocional en el rendimiento académico. Revista de Investigación en Psicología, 5(1), 53-69.

Thornberry, G. (2003). Prelación entre motivación de logro y rendimiento académico en alumnos de colegios limeños de diferente gestión. Persona, 6, 197-216. 